\title{
Expanding the Design Space for Technology-Mediated Theatre Experiences
}

\author{
Molly Jane Nicholas \\ University of California, Berkeley \\ Berkeley, California, USA \\ molecule@berkeley.edu
}

\author{
Stephanie Claudino Daffara \\ University of California, Berkeley \\ Berkeley, California, USA \\ stephaniecd@berkeley.edu
}

\author{
Eric Paulos \\ University of California, Berkeley \\ Berkeley, California, USA \\ paulos@berkeley.edu
}
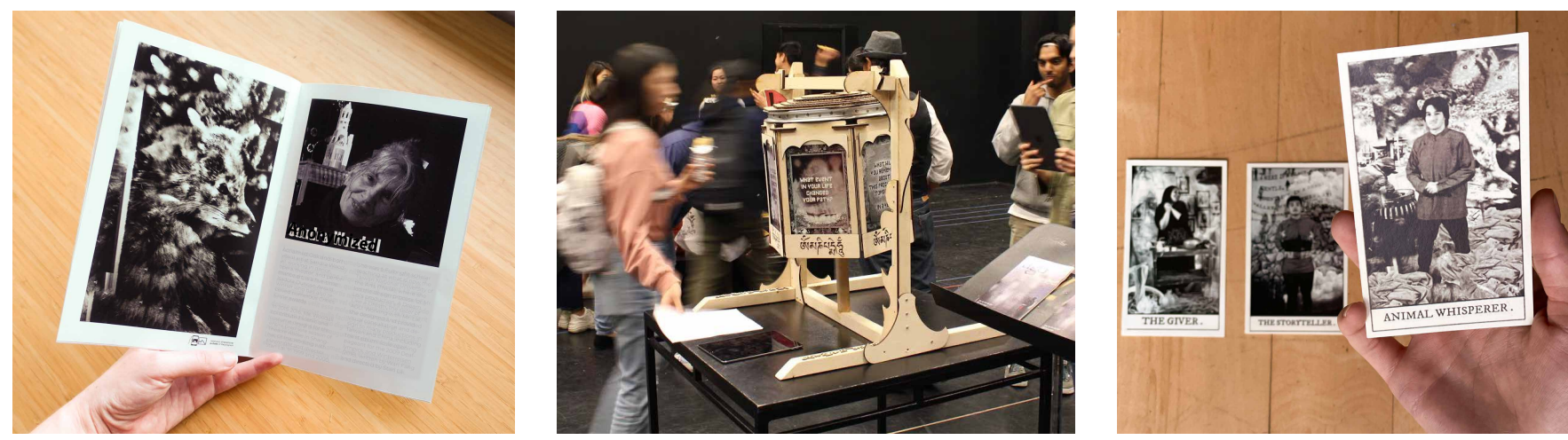

Figure 1: Our three prototypes, embodying the six design guidelines we iteratively developed throughout the four month codesign process. Left: Augmented Playbill, a familiar artifact from the world of theatre, which embodies the affordances of a theatrical visit, augmented to extend the narrative of the production, prompt reflection on the themes of the show, and provide privileged access to behind-the-scenes information. Center: Prayer Wheel, constructed out of laser-cut wood, the prayer wheel resonates with motifs from the play. When scanned, each side reveals audience and cast-member reflections about the themes of the play. Right: Tarot Cards, each depicting a character from the play, which launch an augmented reality scene when scanned by our app.

\begin{abstract}
Work combining live performance and technology often involves incorporating technology directly into the performance as it occurs onstage, including interactive costumes, or performer-controlled sets, lighting or sound. We invert this common approach, developing technology-mediated experiences outside the temporal and spatial confines of a live theatre production. We describe the 4month co-design process with expert theatre practitioners, and detail how the process 1) shaped our design guidelines and 2) expands the discussion around existing best practices for cross-disciplinary collaboration. In the style of research through design, we present three annotated prototypes: the Augmented Playbill, the Prayer Wheel, and Tarot Cards as well as accompanying AR applications to convey the decisions we made and the philosophy we iteratively developed throughout the project. These artifacts also embody our six design guidelines: resonant affordances, extended narrative, reflective interaction, selective reveal, personalized experience, and privileged access.
\end{abstract}

\section{(c) (7) ()}

This work is licensed under a Creative Commons Attribution-Share Alike International 4.0 License.

DIS '21, fune 28-fuly 2, 2021, Virtual Event, USA

(c) 2021 Copyright held by the owner/author(s).

ACM ISBN 978-1-4503-8476-6/21/06.

https://doi.org/10.1145/3461778.3462123

\section{CCS CONCEPTS}

- Human-centered computing $\rightarrow$ Human computer interaction (HCI); Mixed / augmented reality.

\section{KEYWORDS}

Theater; Interactive Performance; Audience Studies; Design Research; Augmented Reality; Mixed Reality

\section{ACM Reference Format:}

Molly Jane Nicholas, Stephanie Claudino Daffara, and Eric Paulos. 2021. Expanding the Design Space for Technology-Mediated Theatre Experiences. In Designing Interactive Systems Conference 2021 (DIS '21), fune 28-fuly 2, 2021, Virtual Event, USA. ACM, New York, NY, USA, 13 pages. https: //doi.org/10.1145/3461778.3462123

\section{INTRODUCTION}

Work combining live performance and technology often involves incorporating technology into the performance itself, including interactive costumes [24, 44], or performer-controlled sets, lighting or sound $[8,9,31]$. These approaches focus on enriching the experience of the performance as it occurs on the stage, staying within the borders of the theatre, and within the time limits of the production. In this work, we explore an inversion of these constraints, identifying opportunities for technology engagement with a live performance at different times and in different places. Our 


\begin{tabular}{|c|c|c|c|c|c|c|}
\hline & $\begin{array}{l}\text { Traditional } \\
\text { Stage } \\
\text { Technology }\end{array}$ & $\begin{array}{c}\text { Augmented } \\
\text { Set, Costumes, } \\
\text { Lighting }\end{array}$ & $\begin{array}{c}\text { Audience } \\
\text { Participation }\end{array}$ & $\begin{array}{l}\text { Production } \\
\text { Support }\end{array}$ & $\begin{array}{c}\text { Rehearsal } \\
\text { Support }\end{array}$ & $\begin{array}{c}\text { This } \\
\text { Project }\end{array}$ \\
\hline $\begin{array}{l}\text { Where Tech } \\
\text { is Seen }\end{array}$ & On Stage & On Stage & On Stage & Backstage & $\begin{array}{l}\text { Backstage } \\
\text { On Stage }\end{array}$ & $\begin{array}{l}\text { Beyond } \\
\text { Stage }\end{array}$ \\
\hline $\begin{array}{c}\text { Controlled } \\
\text { By }\end{array}$ & $\begin{array}{c}\text { Stage } \\
\text { Technicians }\end{array}$ & Performers & Audience & $\begin{array}{l}\text { Stage } \\
\text { Technicians }\end{array}$ & $\begin{array}{l}\text { Performers } \\
\text { Technicians }\end{array}$ & Audience \\
\hline
\end{tabular}

Figure 2: Technology-mediated theatre experiences can be understood in terms of where the technology is seen, and who it is controlled by. This work explores a central, but underexplored aspect: supporting the experience of audience members beyond the onstage experience. Note that both Production Support (technology used by stage technicians backstage during the show) and Rehearsal Support (technology used by performers or stage technicians outside the scope of the show) represent other design spaces that are also underexplored in the literature, though we do not discuss them in this paper.

goal is to use technology to provide opportunities to bring characters to life outside of a production, support reflective theatrical experience beyond the stage, all while embracing the affordances of theatre. In other words, our goal is to integrate tech around a theater experience rather than into it (see Figure 2).

People enjoy creating auxiliary experiences around stories that they love and often enjoy thinking of characters as existing outside the official 'canon' of an author's work. Through a co-design process with expert practitioners, we developed guidelines for designing experiences outside the temporal and spatial confines of a live theatre production. Following best practices for combining technology and performance $[23,24,44]$, we embedded within the development and deployment of a live performance with expert theatre practitioners to prototype technology mediated experiences that extend beyond the stage. In this paper, we describe the 4month intensive co-design "performance-led research in the wild" process [7], identify challenges and opportunities for collaborating with professional theatre-makers, and describe how our design guidelines developed throughout the rehearsal process.

In the style of a research through design paper[49,56], we also present three annotated prototypes: the Augmented Playbill, the Prayer Wheel, and Tarot Cards as well as accompanying AR applications. Together, these convey the decisions we made and the philosophy we iteratively developed throughout the project [21]. These artifacts also embody our six design guidelines: resonant affordances, extended narrative, reflective interaction selective reveal, personalized experience, and privileged access. We evaluate the overall experience with core stakeholders - the Director and the Production Designer, the two most important decision-makers in the theatre production itself - and identify new opportunities for technological engagement within live performance.

\section{RELATED WORK}

\subsection{Technology On Stage}

Collaborations between technologists and performers often involve layering technology on top of the on-stage performance. Saltz [44] presents a thorough taxonomy for incorporating technology into a theatrical production, all of which involve the technology appearing "on stage" in some manner. Bluff and Johnston developed a system for using "motion-tracked human performers in real-time" to control backgrounds and animated graphics projected onto the stage during live shows [8]. They describe how this system and the performers co-evolve over time [9]. Latulipe and collaborators have done extensive work combining dance and technology on stage [10, 29-31]. See Zhou et al. for a thorough retrospective of how technology has been incorporated into dance in HCI over the last two decades [54]. These approaches focus on enriching the experience of the production at the time of the performance and on the stage. In contrast, we seek to extend the experience beyond the timeline and the location of the live show. The project most conceptually related to our work is Magicface, an AR mirror that operates in the backstage of an Opera performance and enables audience members and performers to "step into the character" of a show, enhancing the overall experience [25]. While our work also expands the experience beyond the stage, our work differs from Magicface because our artifacts were meant to be kept by audience members and experienced as they continue to evolve over time.

\subsection{Interactive Live Productions}

A huge variety of work has explored interactivity in live performances across many domains, including music $[32,52]$, theatre [5, $11,14,18,27,38,44]$, sporting events [16, 33], games [22, 34, 47], and audio-visual [35] to select a few.

Cordeiro helpfully summarizes the multitude of forms of interactive art, clarifying the difference between participatory art, where "the audience or visitors' participation is regarded as a necessary and fundamental element for the existence of the artwork", collective art practice where the larger community participates in art production as a means of community engagement and not an end, and interactive art which enables the 'audience' to influence and shape the content or form in real-time [14]. As a few examples of interactive art, Cerratto-Pargman et al. [11,38] designed a system that allows audience members to use mobile devices to shape the outcome of the production. Lee et al. describe a system that facilitates audience participation during a musical performance [32]. Rostami 
et al. identified opportunities for bio-sensing and body-tracking technology that span many forms of interactive performance [41] Works like these often focus on "blurring the distinction" between audience and performance.

Building technology directly into a live production is clearly an incredibly rich design space for creating compelling experiences. In contrast, we understand the unmediated theatrical experience as already interactive. As Kirsty Sedgman writes, "the kind of silent absorbed attention mandated at more traditional theatrical events is something that requires active spectatorial work to achieve" [50]. In other words, the unmediated theatrical audience experience itself is deliberately constructed by the audience, and does not need an extra layer of 'interactivity' layered on top in order to be a rich, interactive experience. See Kirsty Sedgman's work for thorough discussions about this concept from the field of Audience Studies [46, 50], and James Frieze's collection for additional details of the historical context, and thoughtful critique of the widely perceived binary of active vs. passive and traditional vs. contemporary [19]. In this work, we focus on opportunities for design that extend that rich experience beyond the moment of the production, rather than inviting audience participation during the show.

\subsection{Collaborating with Theatre-makers}

When designing technology for live productions, researchers often develop new ways of collaborating throughout the rehearsal process. Barkhuus and Rossitto describe the rehearsal process for an interactive theatre production [5]. Honauer \& Hornecker [24] present a practice-based case study with a local theatre house developing interactive costumes. Their recommendations mirror Gonzalez et al.'s principle of Integrated Process [23]; both emphasize the importance of close collaboration and co-designing aesthetics. Following their recommendations, we were present throughout rehearsals and production to maintain synergy with the aesthetics of the production, and to provide support for any implemented prototypes. We describe additional collaboration recommendations, especially around what types of prototypes are useful for communicating with theatrical professionals, who are accustomed to highly refined aesthetics.

\subsection{Technology Inspired by Theatre}

Spence et al. clearly articulate the differences between various understandings of "performance" as they related to HCI, making a clear distinction between projects that embrace the "theatre of dramas" (as ours does) and those that engage more with the "postdramatic" practices of performance art, which maps more directly onto concerns of HCI. See their paper for thorough and clear discussion [48]. Reeves et al. [39] produced a taxonomy of spectator experience drawn from performance studies: secretive, expressive, magical, suspenseful. Their work describes how these spectator experiences can influence the design of technology. Zhou et al. also considered spectators in their design of Astaire, a collocated hybrid VR dance game [55]. Designers using immersive technologies such as VR have long drawn on arts practices and performing strategies to enhance the experience of mixed reality performances [42]. Researchers have also looked at spectators beyond the stage, and designed systems for crowds at various other events [16, 33, 40].

\section{DESIGN PROCESS}

To better understand the perspectives of multiple stakeholders and goals, and values spanning the lifecycle of development of a live performance, we embedded ourselves within the creative team of a stageplay. We worked directly with actors, directors, and the production team throughout the creation of the production. In this section we detail that process. The final prototypes emerged from our evolving process; we adjusted strategies and techniques as we discovered the best way to work together. We describe both the process and designs simultaneously, describing how each stage shaped the final design guidelines.

3.0.1 Collaboration logistics: Embedding into traditional structure. In a typical theatre production, the production design team includes costumes, set design, sound design, props, lighting, and graphic design. Following best practices for technologists collaborating with artists, in order to stay integrated with the production process $[23,24]$, we joined this set of teams as the 2-person AR design team. Throughout the 4-month creation period, at least one member of each design team, including the AR design team, always attended every rehearsal and production meeting. This kept us in close contact with the evolving artistic production.

3.0.2 Collaborators. Working as part of a team, the main people involved in the design of these prototypes are the following 4 people:

- Director - the internationally acclaimed author of over 40 plays, and is a veteran director of theatre, film, and opera. While he was the final decision-maker for all show elements, he was less involved with daily design aspects.

- Production Designer - a world-renowned designer, she led the vision and execution of the Set, Costume, Lighting, Sound, and AR Design teams. She was the primary day-to-day contact for design discussion and decisions. The Production Designer was also particularly interested in using Augmented and Virtual Reality technologies, because it resonated with the themes of the show.

- Developer/Co-author 1 (D1): previously toured as a professional performer, then worked as a software and hardware engineer, now an $\mathrm{HCI}$ researcher.

- Developer/Co-author 2 (D2): a creative technologist and engineer with a background in film, virtual/augmented reality and HCI research.

The descriptions below are taken from notes taken during the rehearsal process, as well as ongoing interviews and discussions among all the collaborators.

3.0.3 Production details. This production was the world premiere of the Director's latest production. The play begins in a small mountain village near the Himalayas, following the local people's daily lives. Some characters then move to New York, and adjust to life in the big city. The play in its entirety is conceived to be a 4.5 hour performance in four acts. The production involved 28 actors, 6 assistant directors, and 8 designers (one of which was D1, the head AR designer).

The show was performed for three, sold-out nights. A total of 85 audience members saw the production. 

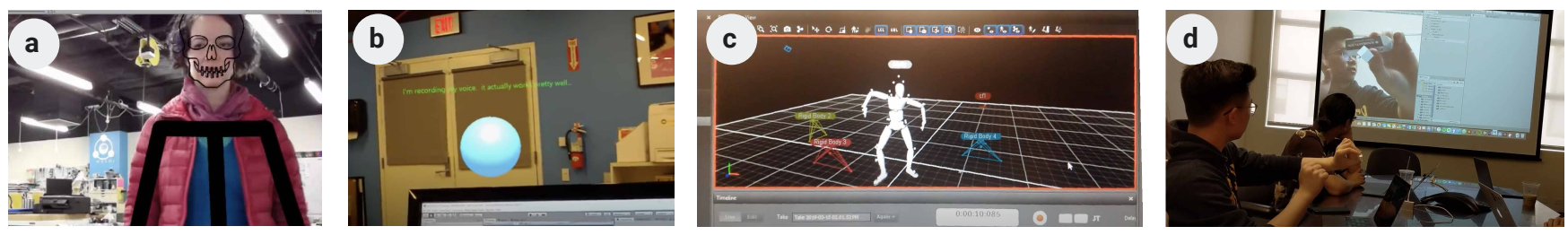

Figure 3: Screen captures of a subset of the lo-fi prototypes D1 and D2 put together during the prototyping stage (see Section 3.3). a) OpenPose skull prototype, which does full-body and face-tracking. The virtual skull overlaid on top of the camera feed represents the Buddhist notion of awareness of death. b) Hololens voice recording demo, showing the impressive capabilities of accurately capturing speech in a noisy room. c) Motion capture, using a full-body setup and mounted trackers. d) A live demo of Vuforia target tracking and interaction.

\subsection{Initial Meeting: Shared philosophy}

Our first meeting with the production designer occurred one month before rehearsals started. In this early meeting, expressing our own ambivalence about how and when it's appropriate to incorporate technology into a live show helped to build rapport. Consider this excerpt from an early email D2 sent to the Production Designer:

Before using a new technology just for the sake of using it you should ask yourself, what is the goal? Who is this experience for and when should they experience it? Why? What value does this interactive piece add to the overall spirit of the performance?

Thoughtfulness around when and why to incorporate technology was a theme in early discussions. At D1's first meeting with the Director, he quickly shared his reluctance around incorporating technology into any theatrical show. He was especially concerned that using phones would distract audience members. We emphatically voiced our agreement, emphasizing our own skepticism about technological solutions in general. Building on his concerns, we discussed potential difficulties with getting folks to learn a new technology, download an app, our shared desire to minimize the 'necessary evil' of instructional signage [14] and other potential challenges around comfort and battery life. Instead of enthusiastically declaiming the potential benefits of technology, we acknowledged potential downfalls, and reframed the production as an experiment.

\subsubsection{Takeaway: Understand Ambivalence, Build Rapport.}

By openly embracing our own ambivalence around technology, we built rapport with our collaborators. Discussing potential issues and downsides early on allowed us all to embrace the production as an experiment, and set our first design guideline: we wanted the affordances of any technology to resonate with existing norms and expectations of theatre (this became our first design guideline, Resonant Affordances). Our approach is an interesting twist on Honauer and Hornecker's recommendation to have an enthusiastic proponent of technology within the organization [24]. Instead, both developers bonded with the Director over skepticism around technology. Of course many theatre-makers embrace new technology in different ways! We encourage designers to embrace the complex implications of introducing any piece of technology into theater, and led with openness to support a discussion about how to make it work well in their context.

\subsection{First week: Technology Enumeration}

During the first few weeks of the design process, we purposefully maintained a sense of openness about what kind of technology we might be able to use, and how we might incorporate it into the production. By collecting a list of existing technology, we thought we'd be enabling an open but grounded conversation around the technological possibilities. While we wanted to stay open to any design options, we were also eager to converge on a specific technology quickly, so that we could finish any implementation early enough that it could be incorporated into the rehearsal process if necessary, as recommended by both Gonzalez et al. [23] and Honauer et al. [24]. We particularly wanted to be able to iterate on designs beyond the lo-fi prototyping stage, since we expected aesthetics to play an especially large role in the final experience. At this point we expected our technology to be part of the actual production, used by the performers.

Our generated list included devices with a high likelihood of working for the show (such as the Hololens), and devices we thought wouldn't work at all (such as the HTC Vive, which is expensive, unwieldy, and requires a full desktop setup). We also included practical information about cost and details about the user experience including field of view, battery life, and wearability. Our design process at this point could be understood as 'problem-solution co-evolution', whereby the designer both a 'problem space' and a 'solution space', with each informing the other [4].

\subsubsection{Takeaway: Build a Shared Understanding.}

While helpful from a logistical point of view, it became clear very quickly - within a few meetings - that there was a lack of shared understanding around what each technology could do, and our lists didn't translate into familiarity with existing options for both the theatre-makers, and the technologists. At the same time, some technology that was new and exciting to us - such as projection mapping - felt like old hat to the Production Designer. The Production Designer also wanted to stay away from any technology that she saw as likely to be co-opted as a cost-saving device (such as using projection mapping to save money on scenery). Instead, she repeatedly emphasized how the technology should extend the narrative of the production, leading to our second design guideline, Extended Narrative. 

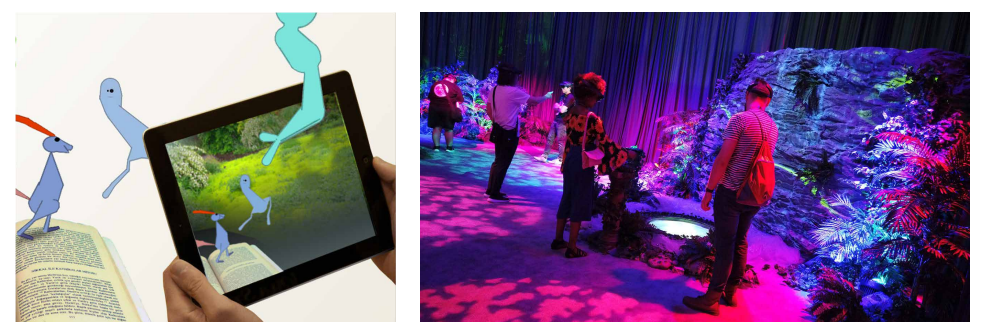

Figure 4: Left: An iOS app called Peck Peck's Journey [1] that served as inspiration for our augmented playbill. Right: An image of the Unreal Garden [3], a Hololens-based augumented reality art exhibit we attended along with the Production Designer. When we visited the Unreal Garden, we were still considering designing an experience that the audience would use during the show, possibly while wearing the Hololens. While we had shown the Production Designer several lo-fi demos that used the Hololens, experiencing a polished version end-to-end helped the Production Designer develop a clearer understanding of both the limitations and opportunities, and helped us as a team better articulate a shared vision and goal for the project (see Section 3.4), which helped us develop our design guidelines (see Section 4), and ultimately led us away from an experience where the audience would wear the Hololens and towards the final prototypes (see Section 5).

\subsection{Month One: Lo-Fi Prototyping}

Following our own prior experience and best practices for 1) technologists working with theatre-makers [24], 2) eliciting early feedback while managing limited resources [45], 3) participatory design practices [37], and 4) prompting innovation and exploration [12, 53] we opted to build lo-fi prototypes (i.e., they rank relatively "low" on all five of McCurdy's dimensions [36], but especially on visual refinement and richness of interactivity). Our goal here was twofold: verify what a given technology option could do, and act as a discussion prompt with the theatre experts. We believed building prototypes would be a helpful way to build a better shared vocabulary.

Throughout the first month of the rehearsal process, we built and shared four primary lo-fi prototypes as part of the brainstorming process. See Figure 3 for a subset of our early proof-of-concept, low-fidelity prototypes. We specifically avoided polishing our early demos, hoping to encourage richer feedback, as recommended by HCI researchers $[12,15,28,36,51,53]$.

\subsubsection{Takeaway: Lo-Fi Prototypes Failed to Build Shared Under- standing.}

While these technical demonstrations were helpful to the technologists as proofs of concept, they proved less useful for communicating with the rest of the design team. Even while examining a functional prototype, the Production Designer frequently asked us to clarify what was possible to implement. Believing that the prototype correctly conveyed both the limitations and possibilities of the technology, we'd optimistically respond "anything", meaning "anything within these limits". What became clear after several such conversations was the lack of shared understanding for what a prototype meant, as well as a lack of clearly articulated goal.

Fundamentally, this represented a lack of shared understanding of what the technology was capable of, a lack of shared vocabulary, and lack of shared vision behind incorporating technology into theatre. Prototypes, while helpful from a technologists perspective, were not helpful for overcoming these barriers. The lack of aesthetic refinement, meant to encourage thoughtful critique, was so offputting to the Production Designer that she hesitated to respond to or critique our work at all. We frequently turned to Youtube, looking for polished and complete examples of similar technology or experiences (see Section 7.2 for further discussion).

\subsection{Month Two: Experiential Immersion}

Once we realized that lo-fi prototypes were failing to help us overcome these barriers, we sought out ways we could experience polished, finished experiences. Wanting to go beyond watching Youtube videos, we found several well-executed AR applications we could experience together. Two had a particularly large impact on our final designs and overall collaboration experience: Peck Peck's Journey, an AR-augmented book [1, 2]; and the Unreal Garden, an experience for Hololens [3] (See Figure 4).

3.4.1 Peck Peck's Journey. Peck Peck's Journey is a simple AR Book experience which uses a mobile phone and a physical book. When a page is scanned with a phone, AR characters appear on the page as viewed through the phone, and they interact with digital elements of the on-page scenery. The AR characters can also be interacted with using your finger on the touch screen. The story progresses as the user flips the book's pages, scanning each page (See Figure 4). The simplicity of the experience, coupled with the highly polished aesthetics, immediately resonated with the Production Designer. We began to see the possibilities of embedding the AR experience into a familiar theatre artifact: the playbill.

3.4.2 Unreal Garden. By far the most impactful experience in terms of shaping our designs was the Unreal Garden. The Unreal Garden was billed as an "interactive, multiplayer mixed reality experience blending a beautiful, psychedelic forest landscape, multiple layers of sound, responsive projections, haptics, and augmented reality. Visitors are immersed within a magical world blending art and entertainment, and inhabited by fantastical flora and fauna" [3] (see Figure 4 for images).

Participants are welcomed to the indoor space, a tall-ceilinged room decorated to look like a lush cave, filled with fake plants, a stream, and dramatic lighting. As a group, we were instructed in the use of Hololens headsets, and then allowed to explore the 


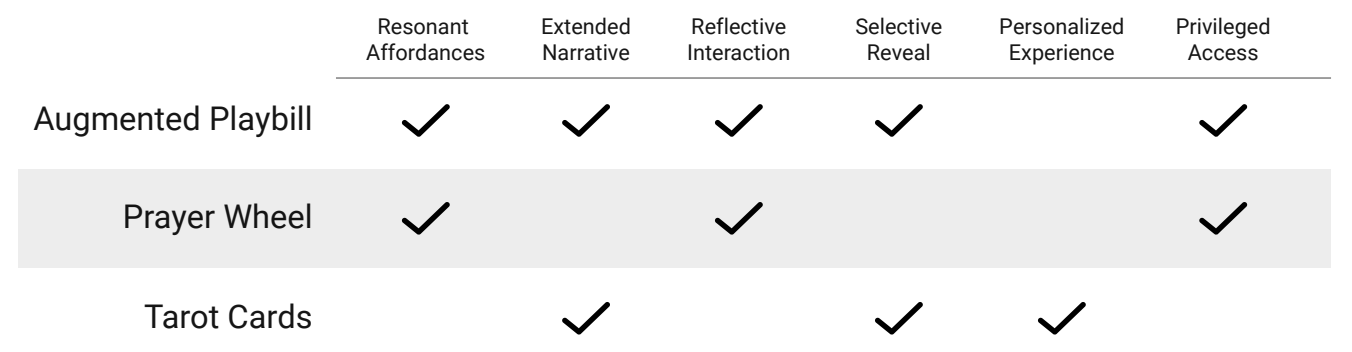

Figure 5: To investigate the whole range of our design guidelines, we instantiated each into more than one prototype. This is a diagram showing which guidelines were built into each prototype.

"interactive" AR exhibit at our own pace. The specifics of the exhibit aren't as relevant as our own discussions afterwards.

Immediately following the experience, we sat down in the lobby for what became an intense, multi-hour discussion about the value of theatre, and how augmented reality might fit into that world. In sharp contrast to earlier discussions, which had felt tentative and polite, the Production Designer immediately launched into a thoughtful, nuanced critique of the entire experience, and Augmented Reality as a medium.

The Production Designer is passionate about the potential of theatre to have an emotional impact, and feels that theatre is one of the only places where people can really "expand their perception". For her, the Unreal Garden was a disappointment; more of a beautiful museum-like display, or "eye candy". She said: "The whole intro, the front door, the ticket setup, everything of the Unreal Garden sets you up for entertainment, not an emotional experience". She went on to emphasize the difference between a theatrical experience which "has a lot of space for imagination" and AR, which she understood as primarily focusing on "showing something more." She described her personal favourite theatrical experiences, which have "so much implied and so much space" to "give room for our own interpretation and our own perspective to it." This discussion became another design guideline, one focused on helping audience members deeply engage in the themes of the production and how it impacted their own life: reflective interaction.

For the Production Designer, the way technology in general, and AR in particular always added content to the world was a barrier to embracing it for theatre ${ }^{1}$. She articulated her concerns beautifully:

Production Designer: What do artists do? We focus attention, while leaving space for imaginative leeway. Theatre is about creating something tangible to respond to. But wearing [a Hololens] or having an iPad is "more real" than what's on stage, and this can then feel like an imposed sense, not belonging to me.

She compared the capabilities of AR with existing theatre tech: "Sure, we can imagine flowers blooming suddenly on stage but well-designed scenery and lighting can already do this." After experiencing the Unreal Garden, she found herself questioning whether

\footnotetext{
${ }^{1}$ We also discussed using AR to remove or block elements from the live on-stage production, a form of "diminished reality" she found extremely compelling, but the post-Unreal Garden discussion led us away from audience members wearing individual headsets due to their isolating nature.
}

AR was appropriate for theatre at all. She wondered if there was "a way to use AR in a way that invites imagination rather than illustrat[es] a secret." This led to another of our design guidelines, selective reveal.

3.4.3 Takeaway: Hi-Fi Prototypes Are Better In Some Contexts.

The polished aesthetics and immersive experience of both Peck Peck's Journey and the Unreal Garden launched a series of much richer discussions. Over the next few weeks, we developed a more complete shared philosophy around the purpose of theatre, and how technology should fit into that, shaped by our shared experiences with these two events, and our own backgrounds. Our experiences suggest that in certain contexts, it may be important to adjust the default methodology, and question existing recommendations that emphasize the value of "low-fi prototypes" for cross-disciplinary collaborations. We found instead that highly polished, aesthetically refined, complete experiences best supported the collaborative experience in this context (see Section 7.2 for further discussion on this).

\section{DESIGN GUIDELINES}

Here we describe the design guidelines we generated throughout the collaborative process in greater detail. Our overall guiding principle, succinctly stated by the Production Designer: "We want something that's a continuation of theatre, not a contradiction."

\subsection{Resonant Affordances}

It's important for the technology to enhance and extend the aesthetics and affordances of the production, not "fight" it. We see this as the "off-stage extension" of Gonzalez et al.'s Aesthetic Harmony [23]. Gonzalez et al. focused on how technology can augment the on-stage production. In contrast, our focus was on the audience experience before and after the show. The notion of resonant affordances encourages designers to take into account not only the themes of the show, but the existing norms of theatre spaces broadly speaking, and how those can influence not only the content, but the interaction techniques used. For example, personal phones are naturally distracting, and using them during the show would break the common theater norm of keeping phones hidden. Maintaining these norms was important for this particular production team, but might be useful to break in another context. We did not expect the audience members of this particular production to be familiar 

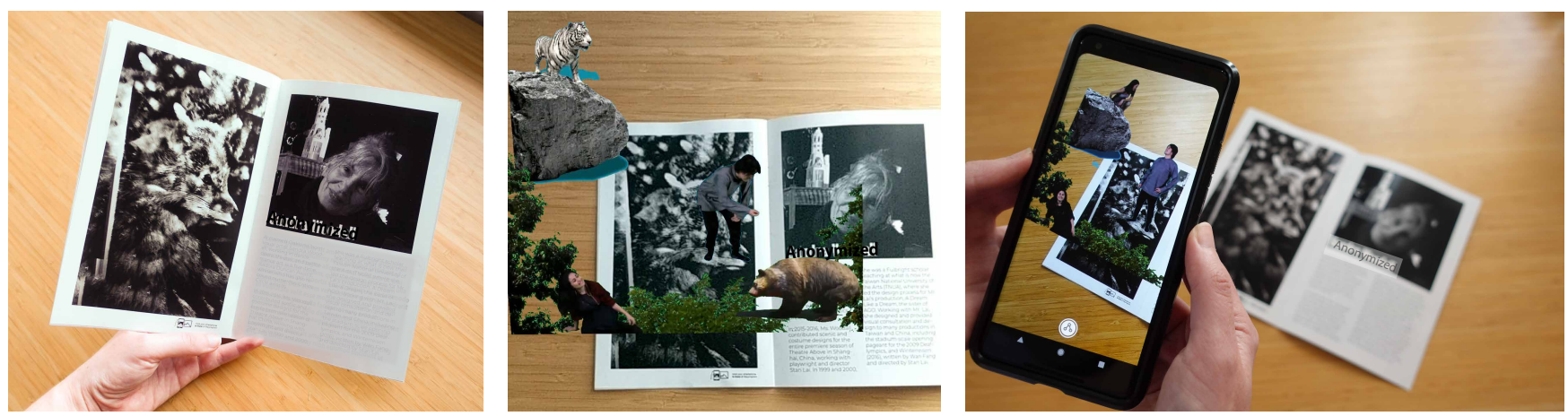

Figure 6: Demonstrating how one particular page of the Augmented Playbill shows a scene from the play when scanned by the phone app, including effects and costumes we were unable to achieve in the live, stage production itself.

with head-mounted displays such as the Hololens, but for another audience that might be reasonable.

This guideline emphasizes allowing the themes and design of the show to help inform the interaction with the technology. For example, if the production is not interactive, the post-show experience doesn't need to be, and doing so might be confusing or jarring.

\subsection{Extended Narrative}

Characters and elements of the show should have a life beyond the production. The content of any technological artifacts should be deeply connected to and extend the existing narrative. Tech should expand opportunities for interaction at either end of the production, and should take advantage of existing theatrical and storytelling techniques for introducing characters and building on the story.

The technology should take the story further than would be possible otherwise. A key element of this for the Production Designer was that the technology should go beyond "just marketing" - she felt very strongly that anything we create should ultimately serve the story. She was particularly drawn to the idea of the character having a life even when you're not looking at it.

\subsection{Reflective Interaction}

While some forms of theatre are meant to be pure escapism, both the Director and the Production Designer emphasized the importance of long-term reflection on and engagement with the themes of the show. As the Production Designer put it:

Production Designer: Reflection completes the idea of theatre.

We wanted to prompt reflection on the personal experience of the show, while supporting lightweight engagement between audience members. By reflection, we don't necessarily mean a serious, focused accounting of one's personal experience. Writing fan fiction about the show, or creating cosplay ${ }^{2}$ of a character would both be activities that could be supported in reflective interactions (though we didn't necessarily expect those to happen for this production because it is so new and had a limited 3-day run; those types of fan-based behaviours take time to establish).

${ }^{2}$ Cosplay is defined as the practice of dressing up as a character from a movie, play, book, or video game.

\subsection{Selective Reveal}

The Production Designer emphasized the importance in theatre of leaving some details to the imagination: "We want something that's charging your imagination, not illustrating everything."

Putting a show on stage is all about choosing what to display and what to keep hidden. Hidden or ambiguous details allow audience members to "complete the story" with their own interpretations - in this way, the Production Designer considers all of theatre a co-created art form, constructed in collaboration with an audience. We wanted our designs to embrace this mindset, and to explicitly invite audience members to add their own experiences to the story.

\subsection{Personalized Experience}

In all theatre, there's a tension between the shared experience of watching a live show together, and the individual experience we all have as humans. Personalizing experiences is a very strong theme in D2's AR/VR work. The more personal an experience feels, naturally the more immersed a user becomes. Since AR and VR are typically viewed through an individual viewer (headset or mobile device), it is an optimal platform for those forms of tailored experiences, but the medium can also be isolating. Broadly speaking, there are two ways an experience can be personalized: 1) the user chooses what they want to interact with and therefore personalizes their own path and 2) the developer knows who the user is because of tracking and tailors the content of the experience to that particular user. We chose to embrace the first option, feeling that this resonated with the sense of agency and personal choice that the Production Designer and Director hoped to engender in the audience. We also sought ways to balance the personalized, individual experience that's often implicit in AR/VR while still supporting the social experience that's core to theatre, see Section 7.3 for further discussion.

\subsection{Privileged Access}

There was a strong tension between the audience desire to have access to process and the artist's desire to fill any available space with more art. In contrast with the Production Designer's primary goal of extending the show's narrative, both D1 and D2 felt that the project represented a unique opportunity to provide access to behind-the-scenes information such as interviews with performers 

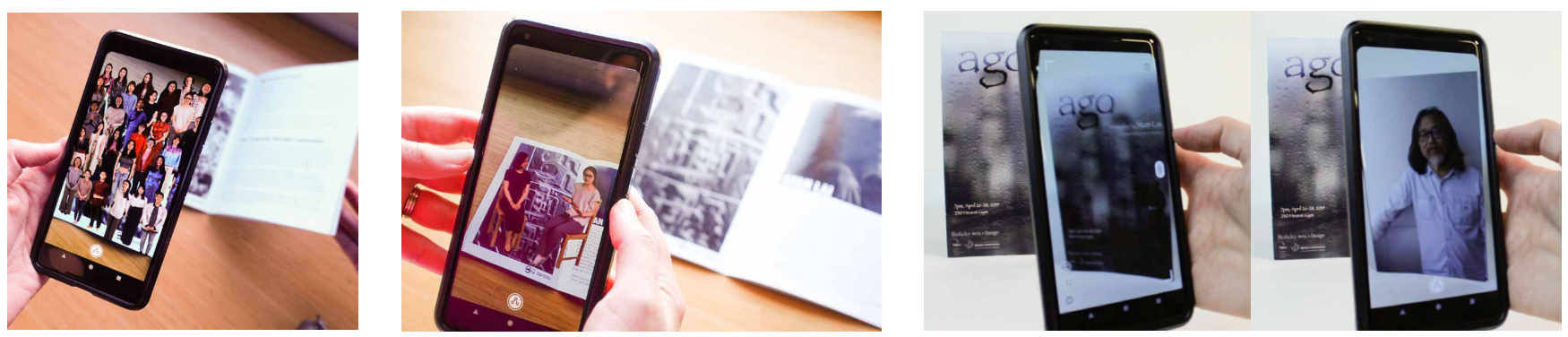

Figure 7: Left: One page of the playbill showed the cast thanking the Director, Production Designer, and backstage crew. Center: Another page of the playbill, which shows cast-member and assistant director interviews when scanned. Right: The cover of the program, which had the same design as the advertisement posters. When scanned, both show the Director inviting the viewer to the show.

and the director. This stemmed from our own experiences as dedicated fans of shows - we have participated in cosplay, created our own fan fiction, and otherwise engaged in various fandoms ${ }^{3}$. The Production Designer initially felt that including "behind the scenes" information was not a novel use of the program. We eventually agreed that dynamically updating the program over time with "the latest" behind-the-scenes shots curated by the performers, including (for example) pictures of the audience from the specific night they attended represented a unique twist on the typical "behind the scenes" documentary: a much more personalized, targeted, and potentially memorable experience.

\section{THREE PROTOTYPES}

Using the design guidelines described above, we developed three artifacts: the Augmented Playbill, the Prayer Wheel, and the Tarot Cards. We describe them below, as an annotated portfolio [20], focusing on the functionality, aesthetics, practicalities of production, motivation, and audience. We explored each design guideline in different ways in each artifact, and covered the entire design space through the instantiation of the artifacts.

\subsection{Augmented Playbill}

Theatrical productions typically provide an informational booklet known as a 'playbill' to audience members as they enter the theatre. These playbills typically contain information about the production including short blurbs about the performers, a note from the director, dramaturgical information and relevant history behind the production. Our design goes beyond this, adding a layer of technology to provide access to additional content.

\subsubsection{Implementation.}

The Augmented Playbill is a printed booklet that acts as both a traditional playbill, and additionally reveals 3D scenes when scanned by a handheld smartphone. Audience members download and install a free app to their phone to access the extra Augmented Reality functionality. The playbill itself contains instructions for downloading and using the application. The phone application automatically recognizes the image on the page and pulls the video data from a

\footnotetext{
${ }^{3} \mathrm{~A}$ fandom is a subculture composed of fans characterized by a feeling of empathy and camaraderie with others who share a common interest.
}

remote database. This video then plays as an overlay on top of the physical playbill. (See Figure 6 and Figure 9).

\subsubsection{Design.}

Mapping to our design guidelines described above, using a playbill helped us embrace existing norms around the classical theatre experience, since playbills are typically only used before the show, during intermission, and after the show. By embedding the technology experience into the playbill, the affordances of this new interaction resonated with expected behaviour in theatre. A recurring theme of the show was seeing across layers of reality, so using Augmented Reality to reveal a new "layer" to the familiar playbill was another resonant affordance.

The augmented playbill extended the narrative of the production by showing scenes that had been cut from the final show enjoyed by the audience, and effects that weren't possible in the show - like snow falling, or characters morphing into animals. We also updated the content of the Augmented Playbill each week by changing the videos that would launch when a certain page of the playbill was scanned. The goal here was to further extend the narrative, and provide a potentially surprising moment of reflective interaction for those who scanned the program after some weeks had passed. By combining the Augmented Reality technology with the playbill - usually experienced as static memorabilia - the augmented playbill was designed to enhance the experience of the audience member long after the performance ended.

The Production Designer wanted to ensure the audience members developed a sense that the characters lived rich lives and continued to evolve even after the show ended, which required finding the right balance of details to selectively reveal through the playbill. For example, although some details of the background of a certain main character were known to the Director, we did not include those in the playbill. Maintaining some mystery was key to a rich experience.

Being theatre fans ourselves, we know how much the audience appreciates having access to behind-the-scenes information. We incorporated some interviews with cast members, recordings of rehearsals, and speeches from the Director into the playbill. This privileged access to behind-the-scenes information is what most audience members expect from extra content. We additionally wanted 

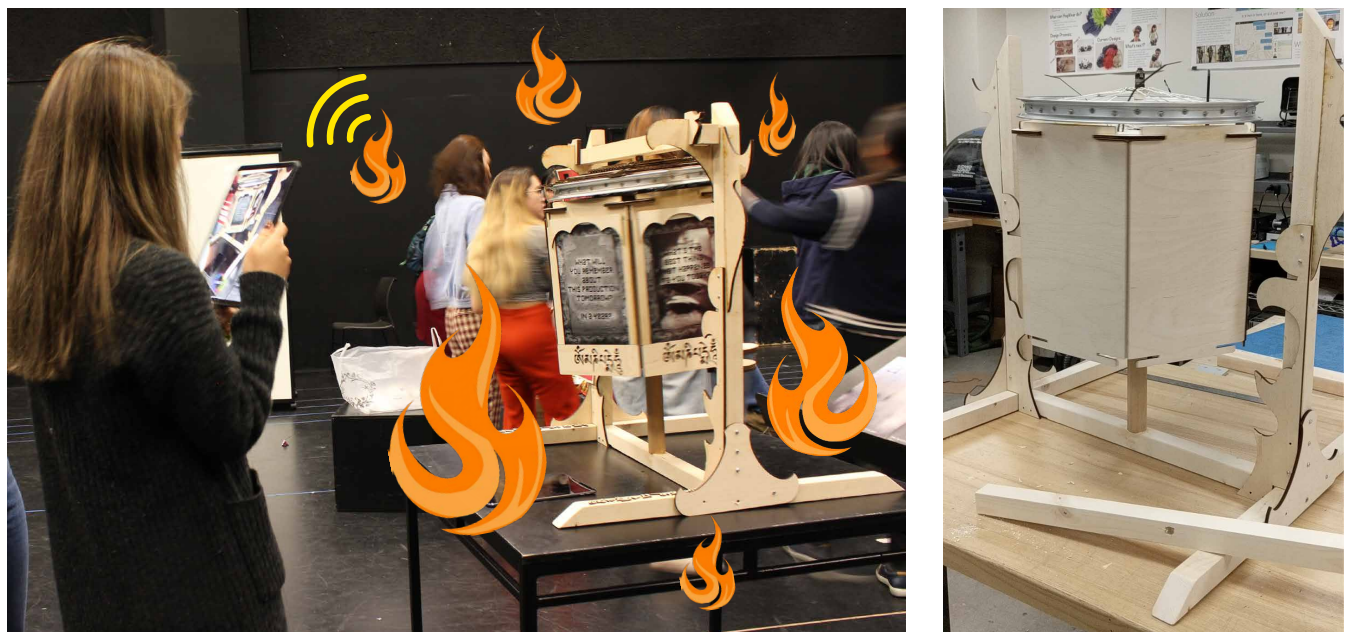

Figure 8: Left: The Prayer Wheel being used and experienced by a cast member. Each side displays a scannable image, containing a question prompt. Once scanned, recordings left by other audience members appear as flames situated in the $3 \mathrm{D}$ coordinate position around the prayer wheel, mirroring the unique $360^{\circ}$ layout of the production. Each flame can be selected, playing the associated recording (shown in yellow). In this image, the flames are added digitally for clarity. Right: Early draft of the Prayer Wheel prototype.

to include more personalized content, including pictures of the audience (taken from back-stage, or on-stage) on the specific night each person attended, or a curated message from the cast on each given night. Our system did not support sending personalized messages like this, but we hope a future version of the project can support these more targeted and potentially more memorable experiences.

\subsection{Prayer Wheel}

This prototype was meant to emphasize reflective interaction with the story, the characters, and the creation of the play. Using motifs from the play we built a model of a Tibetan Prayer Wheel. Prayer wheels are meant to be spun as part of a meditation and prayer practice in the Tibetan culture that was depicted in the show. It was displayed in the lobby and rolled into the main theatre area during intermission (see Figure 8).

\subsubsection{Implementation.}

The Prayer Wheel prototype is composed of a physical prayer wheel and an accompanying augmented reality application. The prayer wheel was built out of laser cut wood, a bicycle wheel, and paper. Before and after each performance we installed the Prayer Wheel in the lobby of the theater.

The prayer wheel has six sides with one question written on each side. The questions on the prayer wheel were carefully selected to both guide audience members to reflect about their own life as well as on their experience watching the play. This represents a reflective interaction. Both Developers generated a set of six questions in collaboration with the Production Designer, including questions such as "Is your best day ahead of you or behind you?", "What will you remember about this production tomorrow? In a year?" and "What's the best thing that happened to you today?". The questions were closely tied to the themes of the play.
To trigger the AR experience, audience members first spin the wheel, scan a question with the tablet device, and record or listen to an audio message responding to that question. Audio messages appear in the AR scene as virtual candle flames. Once a question is scanned, the flames appear in the 3D coordinate position that the audience member is standing at in relation to the prayer wheel. The end result is that after scanning a question, the audience member is surrounded by the thoughts and reflections of other audience members or performers (see Figure 8 for details). Spinning the prayer wheel happens in 'public' - visible to everyone in the lobby.

5.2.2 Design.

Because part of the production takes place in Tibet, having a prayerwheel in the lobby shows aesthetic harmony [23] with the overall production and helps to set the scene for the audience members. The prayer wheel was placed in the lobby to signal that interaction is appropriate, since using it won't interrupt the show, a resonant affordance. Additionally, the fire icons that appeared in a 360 degree layout around an audience member mirrored the unique layout of the production, and reiterated that the production existed in 360 degree space around the audience. All of these represent the resonant affordances of the prayer wheel.

In addition to the audience, the Director and performers also responded to the questions on the prayer wheel. Their recordings were then made available to the audience members, played over the tablet's speakers. This provided audience members privileged access to reflections from the actors on both their own personal lives, as well as their experiences playing their scripted character.

\subsection{Tarot Cards}

Each tarot card depicts a character from the play, printed on highquality cardstock. The same way that audience members might keep memorabilia of events they attend such as a ticket stub, a poster, or 
a flyer, we gave audience members a physical item that they could take home. Each card also launched an AR scene when scanned with our app. The AR scene displayed the life of the characters before and after the duration of the play.

\subsubsection{Implementation.}

The Tarot cards were printed on high-quality, cardstock paper The cards were accompanied by an AR application built in Unity that would play a unique 3D animation upon scanning a card. After many thorough readings of the script, conversations with the actors about their characters and with the play's designer, we generated scenes that the character might have lived in before and after those already in the script, such as a dream-like scene where one character called Caiyun is crying in the snow. We captured the data for these animations during rehearsal. First we took 3D body scans of each actor wearing their character's costume using the iOS app itSeez3D. Then we cleaned up each mesh using Meshlab by first removing any garbage points from the point cloud, then adding a sampling filter (Poisson-disk Sampling). Next, we computed normals for point sets, and finally ran a surface reconstruction filter. Next, we added animations to the fixed mesh using Adobe's Mixamo.

Lastly, we designed and modeled scenes and animations for each character using Unity. We built a custom Unity app using our own code wrapper on top of ARKit and ARCore. This allowed the software to run on any AR-enabled iOS or Android device. Each character had its own Tarot card that served as an image marker that would launch a particular scene when scanned.

\subsubsection{Design.}

Each tarot card launched a window into unseen moments with the characters outside the timeline of the play. This supports our design principle of extended narrative by giving each character a deeper story beyond what was shown in the show. Later, the physical card would not only remind audience members of the performance itself, the scenes would also act as a continuation of the character. The scenes that were launched from the Tarot cards could be changed over time, showing more details of the characters. We were careful to selectively reveal "just enough" information about the characters' backstory, choosing to let audience members' imaginations fill in many details. For example, we did not include any dialogue in the AR scenes so that most of what the characters were actually thinking or saying was still left to the imagination of the audience members.

Many actors chose to the Tarot card that represented the character they had played home as a souvenir, because this represented their own personalized experience of the show.

\section{EVALUATION}

In our ongoing post-production correspondence, all collaborators have discussed what was successful and what wasn't. Both the Director and the Production Designer highly valued the Augmented Playbill and the Prayer Wheel over the Tarot Cards. The Director described the Prayer Wheel as "extremely effective, being an object that reflected on the contents of the play itself, while utilizing the spiritual aspects of the play to bring the audience into a separate but related experience". He also instructed his production company

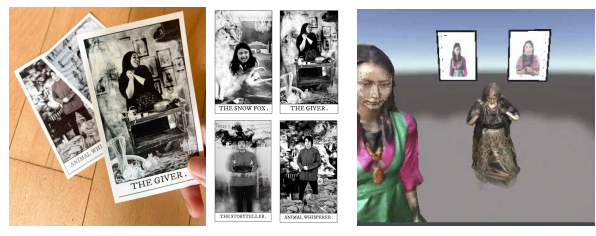

Figure 9: Left: Four of our Tarot Card designs. Each card has details and imagery that depict that character's trajectory throughout the play. Right: The animation scene that plays after scanning the "The Giver" Tarot card, shown in Unity.

to incorporate the Augmented Playbill into the professional production that was staged in Shanghai. The Production Designer found the Prayer Wheel "extremely meaningful and appropriate...simple and effective and well-executed". She felt the Augmented Playbill "represented a powerful use of [AR], one that was exciting to me, in that it worked with the audience to create the poetic furthering of the themes of the piece". All of us agreed the Tarot cards were the least successful, perhaps because they are the least familiar in the theatre context.

Theatre has existed as unmediated live performance for thousands of years. Of course, there is "technology" in theatre but it is integrated into the show, and doesn't mediate the experience for audience members. Developing a rich shared philosophy about the purpose of theatre, technology, and our personal purpose behind combining the two led us to the design of three artifacts whose affordances resonate with theatre itself, but have technology embedded within them and which can then extend and enhance the overall theatrical experience rather than change it.

\section{DISCUSSION}

Although this work discusses, explores, and expands the role of technology in theatrical productions, we see these insights and principles guiding the design of experiences beyond the stage.

\subsection{Applications Beyond Theatre}

Outside of traditional theatre shows, we see opportunities to expand the design of personalized, reflective, tangible technological artifacts in many other contexts. For example, during special theatrical events (a special page in the playbill that is only "unlocked" if an audience member attends a staged reading); a backstage tour (uploading a photograph with a cast member taken at the stage door within the augmented playbill itself for a highly personalized memento); improving the experience of waiting in line for an amusement park ride (a 'passport' that interacts with exhibits as people wait in line, or a premium feature that automatically displays the photographs taken on each ride); in other forms of entertainment (augmenting the ticket stub from a sports game); or book readings (recording a message from the author directly onto the cover of a book rather than getting their signature). Many of these ideas relate to and extend Benford \& Giannachi's concept of the 'trajectory' [6]. 

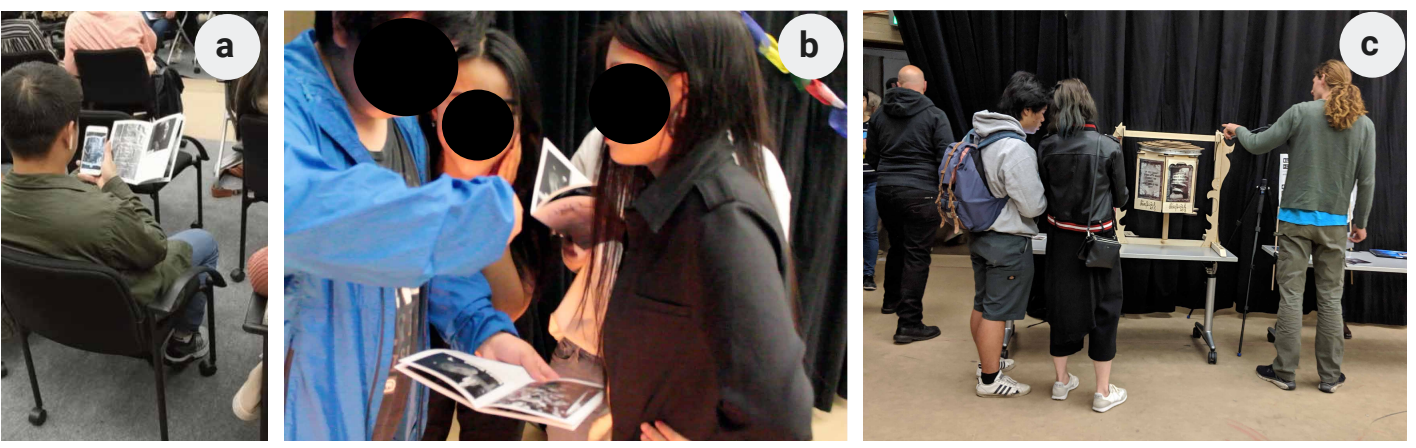

Figure 10: (Left) While we observed prototypical program usage (individual, prior to the show or during intermission), we also (Center) observed social behavior where attendees would gather in groups to explore the program and (Right) prayer wheel together.

\subsection{Implications for Creative Collaborations}

While each step in our collaborative process was fruitful, productive, satisfying, and built rapport and trust even if it didn't directly affect the final design outcome, by far the most impactful was the shared experience of the high fidelity "artifacts", especially the Unreal Garden. While a serendipitous finding, and not something we expected to explore, this aspect of our collaboration contributes to the broader discussions within HCI about the roles of high- and low-fidelity prototypes and cross-discipline collaboration. Lowfidelity prototyping is a well-validated and valuable method for quickly and inexpensively gathering a great deal of information, frequently used to validate designs and and generate insight [12, $15,36,37,45,51,53]$. Compare the prototypes we described in Section 3.3, which score low on all of McCurdy's dimensions of fidelity [36], with the Unreal Garden, which is a fully-realized, paid experience, but is also an extremely high-fidelity prototype ${ }^{4}$ that scores high on all five dimensions. For the Production Designer, a highly accomplished costume designer accustomed to working with extremely aesthetically polished projects, the low level of visual refinement [36] may have played a particularly large role in her negative experience. In our ongoing discussions, she said that she was unable to separate the "content of the demos from the affordances of the technology".

While more work is needed to fully explore this, we speculate that when collaborating with stakeholders that are 1) from disciplines that value highly polished or refined visual aesthetics (costume designers, luthiers, etc) and 2) have less familiarity with the proposed technology in use, a mixed-fidelity prototype that scores high on visual refinement, richness of interactivity, and breadth of functionality [36] may be the best way to introduce new, unfamiliar technology. But the specific implementation may also matter - the similarity with the final potential use-case. In her own words:

Production Designer: The Unreal Garden worked better [than the lo-fi demos], not because the use of the technology was more effective. What worked, what really worked, was having the chance to see the piece with you [D1] and with [D2].

\footnotetext{
${ }^{4}$ According to the developers, who we met at the venue and engaged in an interesting "behind the scenes" discussion.
}

In other words, we agree that it wasn't simply the high level of visual refinement of the Unreal Garden, nor the richness of the interaction (e.g., the fact that the installations there made use of the gesture interaction on the Hololens) - if that were the case, trying any polished application on the Hololens would have prompted this form of deeper discussion. Instead, we speculate that it was the "theatre-like" aspects - the resonant affordances - of the Unreal Garden (arriving at a venue, entering into a special location, the shared experience) that allowed us to reach a much richer place of mutual understanding. This may also be related to the context in which a prototype is evaluated [43]. Ultimately this represents one collaboration in a specific context, and more research is needed to identify best practices for cross-disciplinary collaboration, especially in a theatrical and performance-related context.

\subsection{Social Experiences in AR/VR}

While in-person AR/VR experiences can isolate participants from their local environment due to the affordances of the current mostly head-worn - technology, one of the ways this isolation has been mitigated for mobile AR is through tangible interfaces [13], a known technique to aid in collaboration and cooperation between participants [26]. Both the Augmented Playbill and the Prayer Wheel took advantage of this, and we observed social behavior where attendees would gather in groups to experience the content in both artifacts together (see Figure 10). Especially in the case of the Prayer Wheel, which is physically large, and highly visible, particularly lends itself to interaction by multiple people.

The time outside the dimmed lights of the theatre is more overtly and explicitly social than inside the venue when the house lights are down. The rush of emotions as an audience member emerges into the world again and becomes no longer part of an audience but a person separately living their lives is an underexplored opportunity for compelling, enriching technologically-mediated experiences, which we sought to enrich with our prototypes.

\section{LIMITATIONS AND FUTURE WORK}

For the purposes of this initial collaboration, we focused on the codesign process rather than the audience experience. Our plans for 
future work include building the Prayer Wheel's reflective interaction into the playbill, and allowing audience members to record and listen to messages in the privacy of their own home. However, that introduces concerns about audience members recording vulgar or inappropriate messages such as advertisements or personal attacks. Like Cerratto-Pargman et al. [11], we'd need to add a moderator to manage the input. Our Prayer Wheel design instead had people record their messages "in the open" rather than creating a private sound booth because we hoped that the environmental context of the theatre would strike a balance between socially appropriate behaviour, while still allowing vulnerability in the expression of inner thoughts (However, Helen Freshwater discusses the way these kinds of social affordances inherently limit audience choice in "interactive experiences" [17]). The playbill also introduced changing content, but didn't clearly signal those changes to audience members - finding playful ways to indicate that the stories are evolving would be an interesting next step.

Ultimately our design seeks to expand notions of authorship beyond the Director or Playwright. However, not all authors appreciate or value this form of engagement with their characters and stories. Enabling forms of authorship and engagement by fans may not be appropriate or welcome in all productions, but in cases where authors seek to encourage this form of engagement, we hope these guidelines can shape compelling experiences.

The Production Designer describes her vision for future work: "To me, the next question to address, for scholars, is to investigate the ways that [a] new tool influences the piece - possibly by influencing the question that's asked, possibly by influencing the path of exploration, possibly both. (In costume design an example would be using material to express the content of the piece, then seeing what's revealed, how the costume influences and augments the piece's exploration of its question)". In other words, giving designers new tools during the design process and exploring how their process and output evolves would be a fascinating next step.

\section{CONCLUSION}

This paper explores possibilities for incorporating technology into theater. In collaboration with theatre professionals, we developed three prototypes that demonstrate how AR can expand the experience of attending a theater performance while still resonating with existing theatrical affordances. Throughout the rehearsal process we developed six design guidelines that can be further explored when combining emerging technologies with theater. Additionally we expanded the conversation around the role that low, high, and mixed fidelity prototypes can play in cross-disciplinary collaboration, and found that when collaborating with stakeholders with refined visual aesthetics, high-fidelity prototypes with affordances that resonate with the ultimate goals enabled breakthroughs in our collaboration. We shared some initial observations around opportunities for designing more social Augmented Reality and Virtual Reality experiences. Most importantly, this work seeks to expand the design space for technology-mediated theatre experiences. We hope this work can help future authors motivate their own projects incorporating technology into and around theatrical productions, including production support, rehearsal support, and experiences for audiences that extend beyond the stage (see Figure 2).

\section{ACKNOWLEDGMENTS}

Very special thanks to Stan Lai, Sandra Woodall, the entire cast and production team of $A G O$, the members of the XR@Berkeley Club for their help with early prototyping, everyone at UC Berkeley Arts + Design, everyone at Artivive, and the UC Berkeley Department of Theatre, Dance, and Performance Studies. We also thank Federico Saldarini for his aid with early architectural implementation of our technical framework, the CITRIS Invention Lab for fabrication support, and the anonymous reviewers for their particularly excellent and useful feedback. This research was supported in part by the National Science Foundation Graduate Research Fellowship under Grant No. DGE 1752814.

\section{REFERENCES}

[1] 2015. Peck Peck's Journey: A Picture Book That Spawns Virtual Life. https://www.kickstarter.com/projects/1582488758/peck-pecks-journey-apicture-book-that-spawns-virt/description

[2] 2015. Peck Peck's Journey Home. https://www.youtube.com/watch?v= BhdbhTK9c2o\&t=70s\&ab_channel=WigglePlanet

[3] 2018. The Unreal Garden: Multiplayer Mixed Reality. https://www.ultraleap. com/company/news/case-study/unreal-garden/

[4] Linden J Ball and Bo T Christensen. 2019. Advancing an understanding of design cognition and design metacognition: Progress and prospects. Design Studies 65 (2019), 35-59.

[5] Louise Barkhuus and Chiara Rossitto. 2016. Acting with technology: rehearsing for mixed-media live performances. In Proceedings of the 2016 CHI Conference on Human Factors in Computing Systems. 864-875.

[6] Steve Benford and Gabriella Giannachi. 2012. Interaction As Performance. interactions 19, 3 (May 2012), 38-43. https://doi.org/10.1145/2168931.2168941

[7] Steve Benford, Chris Greenhalgh, Andy Crabtree, Martin Flintham, Brendan Walker, Joe Marshall, Boriana Koleva, Stefan Rennick Egglestone, Gabriella Giannachi, Matt Adams, et al. 2013. Performance-led research in the wild. ACM Transactions on Computer-Human Interaction (TOCHI) 20, 3 (2013), 1-22.

[8] Andrew Bluff and Andrew Johnston. 2017. Storytelling with Interactive Physical Theatre: A Case Study of Dot and the Kangaroo. In Proceedings of the 4th International Conference on Movement Computing (London, United Kingdom) (MOCO '17). ACM, New York, NY, USA, Article 19, 8 pages. https: //doi.org/10.1145/3077981.3078036

[9] Andrew Bluff and Andrew Johnston. 2019. Devising Interactive Theatre: Trajectories of Production with Complex Bespoke Technologies. In Proceedings of the 2019 on Designing Interactive Systems Conference. 279-289.

[10] Erin A Carroll, Danielle Lottridge, Celine Latulipe, Vikash Singh, and Melissa Word. 2012. Bodies in critique: a technological intervention in the dance production process. In Proceedings of the ACM 2012 conference on Computer Supported Cooperative Work. 705-714.

[11] Teresa Cerratto-Pargman, Chiara Rossitto, and Louise Barkhuus. 2014. Understanding audience participation in an interactive theater performance. In Proceedings of the 8th Nordic Conference on Human-Computer Interaction: Fun, Fast, Foundational. 608-617.

[12] Sandy Claes and Andrew Vande Moere. 2017. Replicating an in-the-wild study one year later: Comparing prototypes with different material dimensions. In Proceedings of the 2017 Conference on Designing Interactive Systems. 1321-1325.

[13] Stephanie Claudino Daffara, Anna Brewer, Balasaravanan Thoravi Kumaravel, and Bjoern Hartmann. 2020. Living Paper: Authoring AR Narratives Across Digital and Tangible Media. In Extended Abstracts of the 2020 CHI Conference on Human Factors in Computing Systems. 1-10.

[14] João Cordeiro, Filipa Martins de Abreu, and Gerald Estadieu. 2017. Audience Participation in Interactive Art Systems: Is Instructional Signage a Necessary Evil?. In Proceedings of the 8th International Conference on Digital Arts. 31-37.

[15] Adrien Coyette, Suzanne Kieffer, and Jean Vanderdonckt. 2007. Multi-fidelity prototyping of user interfaces. In IFIP Conference on Human-Computer Interaction. Springer, $150-164$.

[16] Mattias Esbjörnsson, Barry Brown, Oskar Juhlin, Daniel Normark, Mattias Östergren, and Eric Laurier. 2006. Watching the cars go round and round: designing for active spectating. In Proceedings of the SIGCHI conference on Human Factors in computing systems. 1221-1224.

[17] Helen Freshwater. 2011. You say something: Audience participation and the Author. Contemporary Theatre Review 21, 4 (2011), 405-409. https://doi.org/10. 1080/10486801.2011.610308

[18] Gesa Friederichs-Büttner, Benjamin Walther-Franks, and Rainer Malaka. 2012. An unfinished drama: designing participation for the theatrical dance performance Parcival XX-XI. In Proceedings of the Designing Interactive Systems Conference. 
$770-778$.

[19] James Frieze. 2016. Reframing immersive theatre: The politics and pragmatics of participatory performance. In Reframing Immersive Theatre. Springer, 1-25.

[20] Bill Gaver and John Bowers. 2012. Annotated portfolios. interactions 19, 4 (2012) 40-49.

[21] William Gaver. 2012. What should we expect from research through design?. In Proceedings of the SIGCHI conference on human factors in computing systems. ACM, 937-946.

[22] Seth Glickman, Nathan McKenzie, Joseph Seering, Rachel Moeller, and Jessica Hammer. 2018. Design challenges for livestreamed audience participation games. In Proceedings of the 2018 Annual Symposium on Computer-Human Interaction in Play. 187-199.

[23] Berto Gonzalez, Erin Carroll, and Celine Latulipe. 2012. Dance-inspired Technology, Technology-inspired Dance. In Proceedings of the 7th Nordic Conference on Human-Computer Interaction: Making Sense Through Design (NordiCHI '12). ACM, New York, NY, USA, 398-407. https://doi.org/10.1145/2399016.2399078 event-place: Copenhagen, Denmark.

[24] Michaela Honauer and Eva Hornecker. 2015. Challenges for Creating and Staging Interactive Costumes for the Theatre Stage. In Proceedings of the 2015 ACM SIGCHI Conference on Creativity and Cognition (C\&C '15). ACM, New York, NY, USA, 13-22. https://doi.org/10.1145/2757226.2757242 event-place: Glasgow, United Kingdom.

[25] Ana Javornik, Yvonne Rogers, Delia Gander, and Ana Moutinho. 2017. Magicface: Stepping into character through an augmented reality mirror. In Proceedings of the 2017 CHI Conference on Human Factors in Computing Systems. 4838-4849.

[26] Scott R Klemmer, Björn Hartmann, and Leila Takayama. 2006. How bodies matter: five themes for interaction design. In Proceedings of the 6th conference on Designing Interactive systems. 140-149.

[27] Boriana Koleva, Ian Taylor, Steve Benford, Mike Fraser, Chris Greenhalgh, Holger Schnädelbach, Dirk Vom Lehn, Christian Heath, Ju Row-Farr, and Matt Adams. 2001. Orchestrating a mixed reality performance. In Proceedings of the SIGCHI conference on Human factors in computing systems. 38-45.

[28] James A Landay and Brad A Myers. 2001. Sketching interfaces: Toward more human interface design. Computer 34, 3 (2001), 56-64.

[29] Celine Latulipe, Erin A Carroll, and Danielle Lottridge. 2011. Evaluating longitudinal projects combining technology with temporal arts. In Proceedings of the SIGCHI Conference on Human Factors in Computing Systems. 1835-1844.

[30] Celine Latulipe, David Wilson, Sybil Huskey, Berto Gonzalez, and Melissa Word 2011. Temporal integration of interactive technology in dance: creative process impacts. In Proceedings of the 8th ACM Conference on Creativity and Cognition. 107-116.

[31] Celine Latulipe, David Wilson, Sybil Huskey, Melissa Word, Arthur Carroll, Erin Carroll, Berto Gonzalez, Vikash Singh, Mike Wirth, and Danielle Lottridge. 2010. Exploring the design space in technology-augmented dance. In CHI'10 Extended Abstracts on Human Factors in Computing Systems. 2995-3000.

[32] Sang Won Lee, Aaron Willette, Danai Koutra, and Walter S Lasecki. 2019. The effect of social interaction on facilitating audience participation in a live music performance. In Proceedings of the 2019 on Creativity and Cognition. 108-120.

[33] Martin Ludvigsen and Rune Veerasawmy. 2010. Designing technology for active spectator experiences at sporting events. In Proceedings of the 22nd conference of the computer-human interaction special interest group of Australia on computerhuman interaction. 96-103.

[34] Dan Maynes-Aminzade, Randy Pausch, and Steve Seitz. 2002. Techniques for interactive audience participation. In Proceedings. Fourth IEEE International Conference on Multimodal Interfaces. IEEE, 15-20.

[35] Leon McCarthy. 2016. Steering Audience Engagement During Audio-Visual Performance. Ph.D. Dissertation. Northumbria University.

[36] Michael McCurdy, Christopher Connors, Guy Pyrzak, Bob Kanefsky, and Alonso Vera. 2006. Breaking the fidelity barrier: an examination of our current characterization of prototypes and an example of a mixed-fidelity success. In Proceedings of the SIGCHI conference on Human Factors in computing systems. 1233-1242.

[37] Michael J. Muller. 1991. PICTIVE - An exploration in participatory design. Con ference on Human Factors in Computing Systems - Proceedings (1991), 225-231. https://doi.org/10.1145/108844.108896

[38] Charles B Owen, Alison Dobbins, and Lisa Rebenitsch. 2013. Theatre Engine: Integrating mobile devices with live theater. In Proceedings of International Conference on Advances in Mobile Computing \& Multimedia. 378-386.

[39] Stuart Reeves, Steve Benford, Claire O'Malley, and Mike Fraser. 2005. Designing the spectator experience. In Proceedings of the SIGCHI conference on Human factors in computing systems - CHI '05. ACM Press, Portland, Oregon, USA, 741. https://doi.org/10.1145/1054972.1055074

[40] Stuart Reeves, Scott Sherwood, and Barry Brown. 2010. Designing for crowds. In Proceedings of the 6th Nordic Conference on Human-Computer Interaction: Extending Boundaries. 393-402.

[41] Asreen Rostami, Donald McMillan, Elena Márquez Segura, Chiara Rossito, and Louise Barkhuus. 2017. Bio-sensed and embodied participation in interactive performance. In Proceedings of the Eleventh International Conference on Tangible, Embedded, and Embodied Interaction. 197-208.

[42] Asreen Rostami, Chiara Rossitto, and Annika Waern. 2018. Frictional Realities: Enabling Immersion in Mixed-Reality Performances. In Proceedings of the 2018 ACM International Conference on Interactive Experiences for TV and Online Video. 15-27.

[43] Antti Salovaara, Antti Oulasvirta, and Giulio Jacucci. 2017. Evaluation of Prototypes and the Problem of Possible Futures. In Proceedings of the 2017 CHI Conference on Human Factors in Computing Systems. 2064-2077.

[44] David Z. Saltz. 2001. Live Media: Interactive Technology and Theatre. Theatre Topics 11, 2 (Sept. 2001), 107-130. https://doi.org/10.1353/tt.2001.0017

[45] Juergen Sauer and Andreas Sonderegger. 2009. The influence of prototype fidelity and aesthetics of design in usability tests: Effects on user behaviour, subjective evaluation and emotion. Applied ergonomics 40, 4 (2009), 670-677.

[46] Kirsty Sedgman. 2016. Locating the audience: How people found value in National Theatre Wales. Intellect Books.

[47] Joseph Seering, Saiph Savage, Michael Eagle, Joshua Churchin, Rachel Moeller, Jeffrey P Bigham, and Jessica Hammer. 2017. Audience participation games: Blurring the line between player and spectator. In Proceedings of the 2017 Conference on Designing Interactive Systems. 429-440.

[48] Jocelyn Spence, David Frohlich, and Stuart Andrews. 2013. Performative experience design: where autobiographical performance and human-computer interaction meet. Digital Creativity 24, 2 (2013), 96-110.

[49] Pieter Jan Stappers and Elisa Giaccardi. 2017. Research through design. The encyclopedia of human-computer interaction (2017), 1-94.

[50] Isabel Stuart. 2020. The Reasonable Audience: Theatre Etiquette, Behaviour Policing, and the Live Performance Experience: by Kirsty SedgmanCham, Switzerland: Palgrave Pivot, 2018, xi+ 174 pp, ISBN 9783319991658 (hardback).

[51] Robert A Virzi, Jeffrey L Sokolov, and Demetrios Karis. 1996. Usability problem identification using both low-and high-fidelity prototypes. In Proceedings of the SIGCHI Conference on Human Factors in Computing Systems. 236-243.

[52] Andrew M Webb, Chen Wang, Andruid Kerne, and Pablo Cesar. 2016. Distributed liveness: understanding how new technologies transform performance experiences. In Proceedings of the 19th ACM Conference on Computer-Supported Cooperative Work \& Social Computing. 432-437.

[53] Wendie Wulff, Shelley Evenson, and John Rheinfrank. 1990. Animating interfaces. Proceedings of the 1990 ACM Conference on Computer-Supported Cooperative Work, CSCW 1990 October (1990), 241-254. https://doi.org/10.1145/99332.99358

[54] Qiushi Zhou, Cheng Cheng Cheng Chua, Jarrod Knibbe, Jorge Goncalves, and Eduardo Velloso. 2021. Dance and Choreography in HCI: A Two-Decade Retrospective. In Proceedings of the 2021 CHI Conference on Human Factors in Computing Systems (Yokohama, Japan) (CHI '21). Association for Computing Machinery, New York, NY, USA, Article 262, 14 pages. https://doi.org/10.1145/3411764.3445804

[55] Zhuoming Zhou, Elena Márquez Segura, Jared Duval, Michael John, and Katherine Isbister. 2019. Astaire: A Collaborative Mixed Reality Dance Game for Collocated Players. In Proceedings of the Annual Symposium on Computer-Human Interaction in Play. 5-18.

[56] John Zimmerman, Jodi Forlizzi, and Shelley Evenson. 2007. Research through design as a method for interaction design research in HCI. In Proceedings of the SIGCHI conference on Human factors in computing systems. ACM, 493-502. 